\title{
Influence of nano-AIN particles on thermal conductivity, thermal stability and cure behavior of cycloaliphatic epoxy/trimethacrylate system
}

\author{
J. H. Yu, J. K. Duan, W. Y. Peng, L. C. Wang, P. Peng, P. K. Jiang* \\ Department of Polymer Science and Engineering and Shanghai Key Lab of Electrical Insulation and Thermal Aging, \\ Shanghai Jiao Tong University, Shanghai 200240, People's Republic of China
}

Received 30 July 2010; accepted in revised form 9 October 2010

\begin{abstract}
We have prepared a series of nano-sized aluminium nitride (nano-AlN)/cycloaliphatic epoxy/trimethacrylate (TMPTMA) systems and investigated their morphology, thermal conductivity, thermal stability and curing behavior. Experimental results show that the thermal conductivity of composites increases with the nano-AlN filler content, the maximum value is up to $0.47 \mathrm{~W} /(\mathrm{m} \cdot \mathrm{K})$. Incorporation of a small amount of the nano-AlN filler into the epoxy/TMPTMA system improves the thermal stability. For instance, the thermal degradation temperature at 5\% weight loss of nano-AlN/ epoxy/TMPTMA system with only $1 \mathrm{wt} \%$ nano-AlN was improved by $\sim 8^{\circ} \mathrm{C}$ over the neat epoxy/TMPTMA system. The effect of nano-AlN particles on the cure behavior of epoxy/TMPTMA systems was studied by dynamic differential scanning calorimetry. The results showed that the addition of silane treated nano-AlN particles does not change the curing reaction mechanism and silane treated nano-AlN particles could bring positive effect on the processing of composite since it needs shorter pre-cure time and lower pre-temperature, meanwhile the increase of glass transition temperature of the nanocomposite improves the heat resistance.
\end{abstract}

Keywords: polymer composites, epoxy, nano-AlN

\section{Introduction}

In recent years, polymer composite materials with excellent thermal conductivity have attracted increasing attention because the amount of heat generated in electronic devices is getting larger and larger, leading manufactures to seek for new composites that can remove the heat efficiently form the devices $[1,2]$. Epoxy resins are widely used as matrices in the manufacturing process of reinforced composites, adhesives and surface coatings, high voltage electrical insulation materials, electronic components and packaging because of their high strength, stiffness, good thermal stability, and excellent adhesion and electrical insulating properties [3-5]. As the thermal conductivity of epoxy systems is very low (about $0.2 \mathrm{~W} /(\mathrm{m} \cdot \mathrm{K})$ ), thermally conductive fillers are added to these composites in order to dissipate the heat generated in electronic devices [6]. Various kinds of fillers, such as metals and metal oxides [7, 8], aluminum nitride (AlN) [9-11], boron nitride (BN) [12], and silicon carbide ( $\mathrm{SiC}$ ) [13] have been applied to prepare thermally conductive polymer composites. Among them, AlN is a nontoxic, low cost substance, readily available as high purity powder. On the one hand, because of the low coefficient of thermal expansion (CTE) and the high thermal conductivity $(150-300 \mathrm{~W} /(\mathrm{m} \cdot \mathrm{K}))$ of AlN, AlN filled composite materials have attracted much attention in an attempt to reduce the CTE and thermal resistivity of polymer composites [14]. 
In a previous paper, our research group have reported the preparation and characterization of epoxy/trimethylol-1,1,1-propane trimethacrylate (TMPTMA) system $[15,16]$. In this study, nanoAlN particles with an average particle size of $50 \mathrm{~nm}$ were used with epoxy/TMPTMA system as the base system. Nano-AlN particles were pretreated with a silane coupling agent, which was employed to enhance the compatibility between the nano-AlN particles and the epoxy/TMPTMA system, as well as to prevent the agglomeration of the nano-AlN particles. By studying thermal conductivity, thermal stability, and curing behavior of nano-AlN/epoxy/ TMPTMA system, we expect to learn comprehensive and in-depth understanding of the thermophysical properties and curing behavior of this system.

\section{Experimental}

\subsection{Materials}

The raw materials and corresponding specifications of epoxy resin, curing agent, latent accelerator, modifier agent, initiator and filler are given in Table 1.

\subsection{Surface modification of nano-AIN particles}

The nano-AlN particles were dried in a vacuum oven at $180^{\circ} \mathrm{C}$ for $24 \mathrm{~h}$ and appropriate amount of the silane $(0.5-1 \mathrm{wt} \%$ based on the weight of AlN particles) was added into a $500 \mathrm{ml}$ three-necked flask, equipped with a mechanical stirrer and a reflux condenser, and mixed in high purity acetone $(5 \mathrm{wt} \%$ based on the weight of silane) by stirring at 110 $120^{\circ} \mathrm{C}$ for at least $4 \mathrm{~h}$. After filtration, the silane treated powders were dried in a vacuum oven at $120^{\circ} \mathrm{C}$ for $2 \mathrm{~h}$ to remove the solvent and the silane molecules that were not well bonded and thus would not significantly contribute to the joint strength. The probable schematic reaction between nano-AlN particles and GPTMS is indicated in Figure 1.

\subsection{Sample preparation}

Firstly, epoxy resin (100 parts by weight [pbw]) and latent accelerator $(0.5 \mathrm{pbw})$ were weighing and mixed vigorously at $160^{\circ} \mathrm{C}$ for about 10 min until the latent accelerator was dissolved completely in the epoxy resin. Then, the blends of epoxy resin and accelerator were rapidly cooled to the ambient temperature; this was followed by the addition of $90 \mathrm{pbw}$ curing agent and suitable amounts of the initiator and modifier agent mixing for about $30 \mathrm{~min}$. At last a specified quantity of silane treated nano-AlN particles were added into the blend and the mixture was dispersed by sonication for 1 hour at ambient temperature. The specimens with the compositions listed in Table 2 in detail.

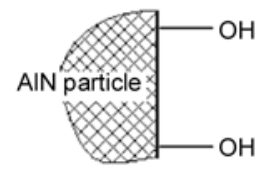<smiles>CO[Si](CCCOC1CO1)(OC)OC</smiles>
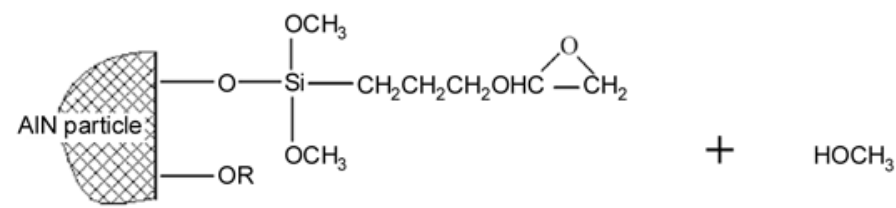

Figure 1.The schematic reactions of AlN particles and GPTMS

Table 1. The detailed raw materials

\begin{tabular}{|c|c|c|c|}
\hline Materials & Abbreviation & Purity & Supplier \\
\hline $\begin{array}{l}\text { 3, 4-epoxycyclohexylmethy-(3', 4'- } \\
\text { epoxy)cyclohexane carboxylate }\end{array}$ & CER & $>98 \%$ & DOW Chemical, USA \\
\hline methyl-hexahydrophthalic anhydride & MeHHPA & $>98 \%$ & Shanghai Li Yi Science \& Technology Development Co. Ltd., China \\
\hline neodymium (III) acetylacetonate & $\mathrm{Nd}(\mathrm{III}) \mathrm{acac}$ & $>99 \%$ & Qinyang Tianyi Chemical Co., Ltd., China \\
\hline trimethylolpropane trimethacrylate & TMPTMA & $>98 \%$ & Jinshi Tech-development Co., Ltd., China \\
\hline dicumyl peroxide & DCP & $>99 \%$ & Qinyang Tianyi Chemical Co., Ltd., China \\
\hline 3-glycidoxypropyltrimethoxy silane & GPTMS & $>98 \%$ & Dow Corning Company, USA \\
\hline aluminum nitride & AlN & $>99 \%$ & Hefei Kaier Nanometer Technology Development Co., Ltd., China \\
\hline
\end{tabular}


Table 2. Formulation of experiment (parts by weight [pbw])

\begin{tabular}{|c|c|c|c|c|c|c|}
\hline System & CER & MeHHPA & Nd(III)AcAc & TMPTMA & DCP & nano-AIN \\
\hline A1 & 100 & 90 & 0.5 & 20 & 0.2 & 0 \\
\hline A2 & 100 & 90 & 0.5 & 20 & 0.2 & 1 \\
\hline A3 & 100 & 90 & 0.5 & 20 & 0.2 & 3 \\
\hline A4 & 100 & 90 & 0.5 & 20 & 0.2 & 5 \\
\hline A5 & 100 & 90 & 0.5 & 20 & 0.2 & 10 \\
\hline A6 & 100 & 90 & 0.5 & 20 & 0.2 & 15 \\
\hline A7 & 100 & 90 & 0.5 & & 20.2 \\
\hline
\end{tabular}

\subsection{Characterizations and measurements}

Field emission scanning electron microscope (FESEM, JEOL JEM-7401, Tokyo, Japan) was used to observe the dispersion of the nanoparticles in the composite samples. Samples were sputtered with thin layers of gold to avoid the accumulation of charge.

Transmission electron microscopy (TEM, JEOL JEM-2100, Tokyo, Japan) was utilized to analyze the morphology of the silane treated AlN particles at $120 \mathrm{kV}$ under low-dose conditions. The AlN/acetone solution was dropped on a copper grid and subsequently the solvent was evaporated in an oven.

FTIR spectrum was recorded in $\mathrm{KBr}$ pellets on a Paragon 1000 (Perkin Elmer, Inc.,USA) using a resolution of $4 \mathrm{~cm}^{-1}$, and transmission measurements was employed.

LFA 447 Nanoflash (NETZSCH, Germany) was employed to automatically determine the thermal conductivity according to ASTM E1461, using the measured heat capacity and thermal diffusivity, with separately entered density data. Samples were prepared in cylindrical shape of $12.7 \mathrm{~mm}$ in diameter and $1.0-2.0 \mathrm{~mm}$ in thickness.

TGA (NETZSCH TG 209 F3, Germany) was used to investigate the thermal stability of the composites. The weight samples was approximately $10 \mathrm{mg}$ and all the measurements were carried out under nitrogen atmosphere. Dynamic runs were carried out from 50 to $700^{\circ} \mathrm{C}$ at a heating rate of $10^{\circ} \mathrm{C} / \mathrm{min}$. Dynamic DSC (NETZSCH DSC 200 F3, Germany) measurements were performed at different heating rates of $5,10,15$, and $20 \mathrm{~K} / \mathrm{min}$ over a temperature range of $30-300^{\circ} \mathrm{C}$. The reaction was considered to be complete when the rate curve leveled off to a baseline. The exotherm was measured under a nitrogen flow rate of $10 \mathrm{ml} / \mathrm{min}$. The exotherm baseline was corrected via data in chamber. The cured sample was left in the DSC cell and cooled to $30^{\circ} \mathrm{C}$, and then the cured sample was scanned at $20 \mathrm{~K} / \mathrm{min}$ to determine the glass transition temperature $\left(T_{\mathrm{g}}\right)$ of the reacted product. The initial temperature of the heat flow step of the second diagram was taken to be the $T_{\mathrm{g}}$. The total area under the exotherm curve, based on the extrapolated baseline at the end of the reaction, was used to calculate the heat of reaction, $\Delta H[\mathrm{~J} / \mathrm{g}]$.

\section{Results and discussion}

\subsection{AlN characterization}

In this study, to enhance the dispersion and interfacial adhesion between the AlN nanoparticles and epoxy matrix, a silane monomer, 3-glycidoxypropyl trimethoxy silane (GPTMS) has been chosen as a coupling agent to functionalize AlN nanoparticles. The chosen silane has two different functional groups, one of which is reactive with the epoxy resin and the other reacts with the surface of AlN nanoparticles. GPTMS can hydrolyze in aqueous solution (e.g. the acetone as used in the present study, where a small amount of water is present) and its methoxy groups will transform into hydroxyl groups. Afterwards these hydroxyl groups react with those on the surface of AlN nanoparticles, then the active coating of nano-AlN particles are obtained. The possible reaction scheme between GPTMS and nanoAlN particles can be seen in Figure 1. The epoxide groups at the other ends of silane can react with the epoxy during the curing process. The dispersion of AlN nanoparticles is thus enhanced by the silane coating. Thus, the interacting force between the AlN nanoparticles and epoxy matrix is improved because the chemical bonding between the AlN nanofillers and the epoxy matrix is enhanced.

Microscopy is very useful for the characterization of generated filler structures. The TEM images obtained for the as received nano-AlN and silane treated nano-AlN powders are compared in Figure 2. Comparison of TEM images (a) and (b) shows that silane treated nano-AIN particles display that 

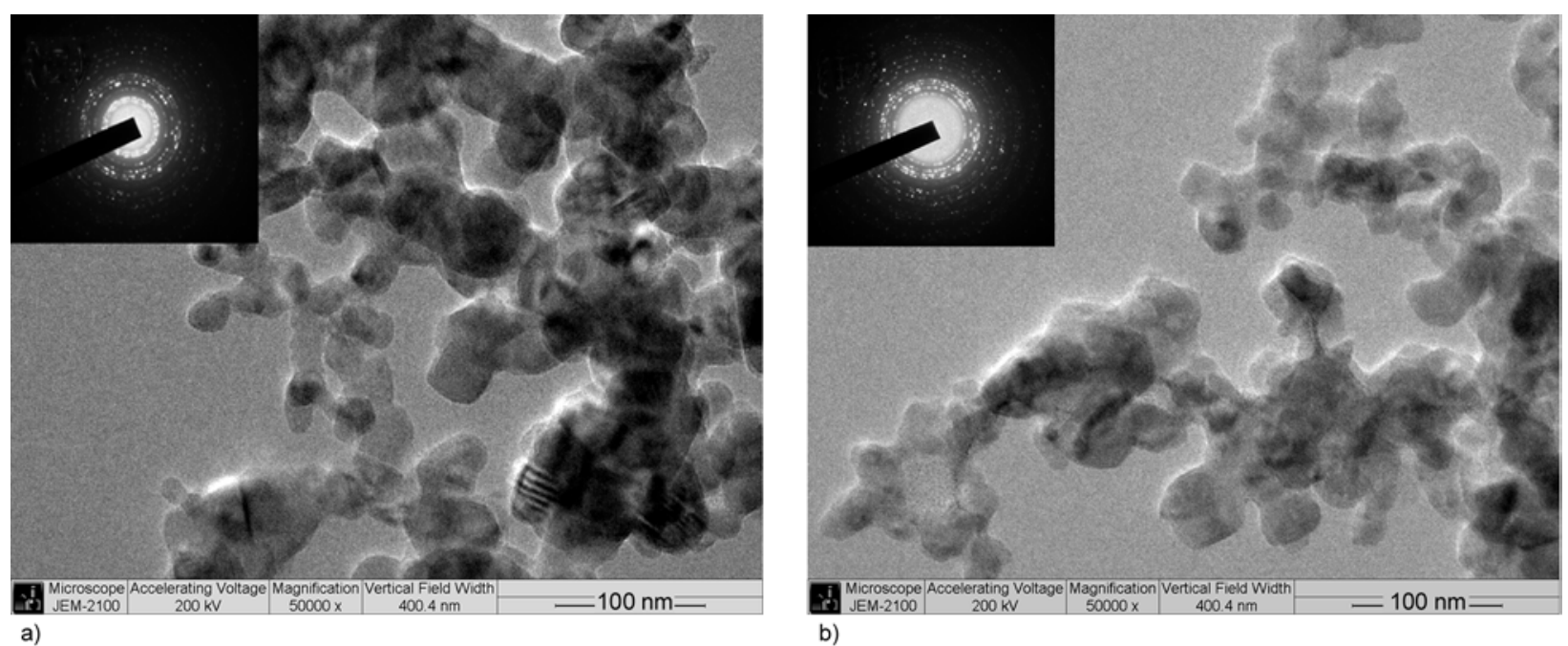

Figure 2. TEM micrograph and corresponding SAED patterns (insets) of (a) as received nano-AIN and (b) silane treated nano-AlN

the surface modification dramatically affects the aggregate particle size. The inset in Figure 2 illustrates the identical selected area electron diffraction (SAED) patterns for both AlN powders, which indicates that the silane treatment has modified only the nano-AIN particle surface leaving the particle core structure intact.

As shown in Figure 3a, the as received nano-AlN particles show a much strong absorption at $v=$ $3200-3500 \mathrm{~cm}^{-1}$, which may be attributed to hydroxyl group $(-\mathrm{OH})$ peak stretching. The band at $v=1641 \mathrm{~cm}^{-1}$ is attributed to $-\mathrm{NH}-$ group vibration, which indicates that nano-AlN particles have the higher affinity and reactivity to moisture and water. Therefore, the surface treatment has been undertaken to prevent the nano-AlN particles from hydrolyzing. The spectra of silane-modified AlN nanoparticles are very similar to those of raw nano-

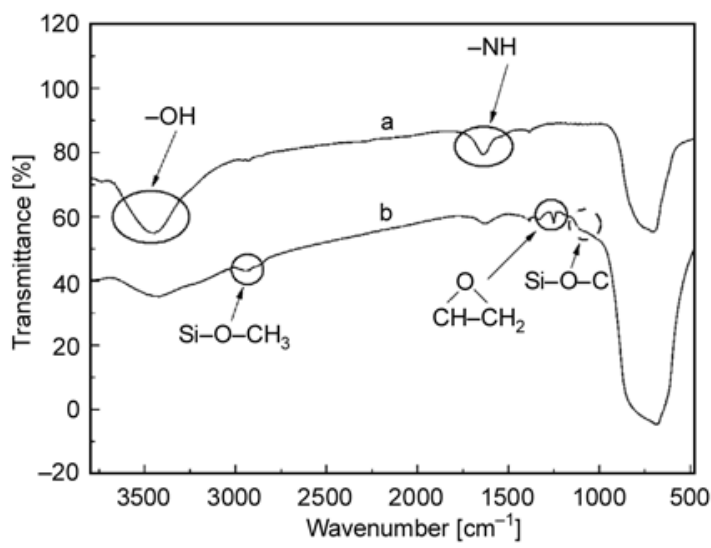

Figure 3. FT-IR spectrum of as received nano-AIN (a) and silane treated nano-AlN (b)
AlN particles, but some differences can still be detected. From Figure 3b, the stretching vibration band of ether group is found in the region 1050$1150 \mathrm{~cm}^{-1}$. The band at $2990 \mathrm{~cm}^{-1}$, attributed to methylene groups, is stronger than that of the raw nano-AlN particles. The absorption bands of epoxy groups at $v_{\mathrm{as}}\left(\mathrm{CH}_{2}\right)=3003 \mathrm{~cm}^{-1}, v_{\mathrm{b}}\left(\mathrm{CH}_{2}\right)=1479 \mathrm{~cm}^{-1}$, $v(\mathrm{C}-\mathrm{O})=1225 \mathrm{~cm}^{-1}$ can be also observed. In addition, the absorption intensity of the bands at $v=$ $3200-3500 \mathrm{~cm}^{-1}$ and $v=1641 \mathrm{~cm}^{-1}$, which are assigned to hydroxyl group and amine group, respectively, can be found to apparently decrease. These changes of characteristic peaks indicate that GPTMS has already been grafted successfully on the surface of nano-AlN particles.

The morphology of the fractured surfaces for A1 and A4 are shown in Figures $4 \mathrm{a}$ and $4 \mathrm{~b}$, respectively. In the case of the neat epoxy/TMPTMA system, the fractured paths of river-like patterns can be observed, indicating brittle fracture. The nanocomposite fails in brittle manner and silane treated nano-AlN particles are seen to be separated and uniformly embedded in the matrix. The inset in Figure $4 \mathrm{~b}$ shows that no obvious naked particles and inorganic clusters are present, indicating good interfacial adhesion between the particles and polymer matrix after silane pretreatment. The scheme for epoxy/TMPTMA system filled with silane treated nano-AlN is shown in Figure 4c. It represents that the covalent bridge bonds are formed between silane treated nano-AIN fillers and the epoxy resin. 


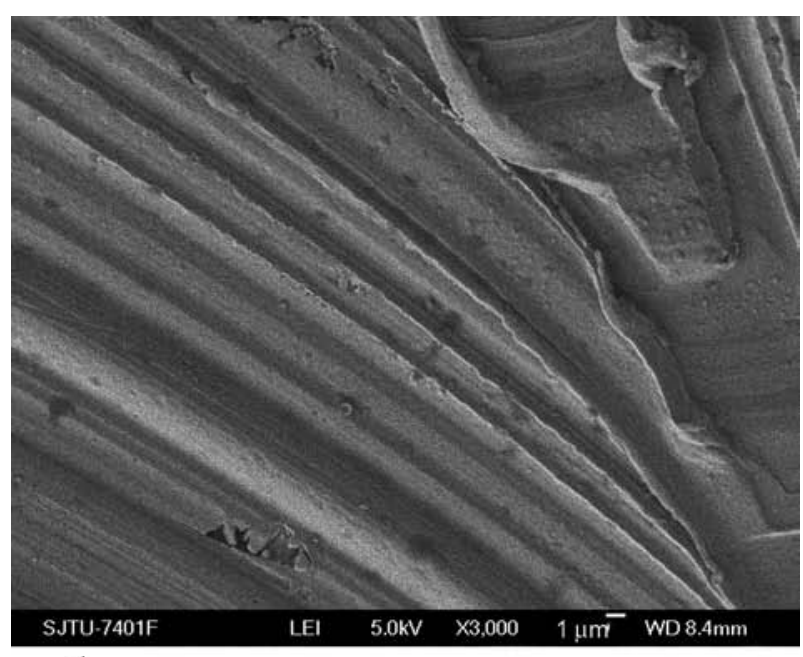

a)

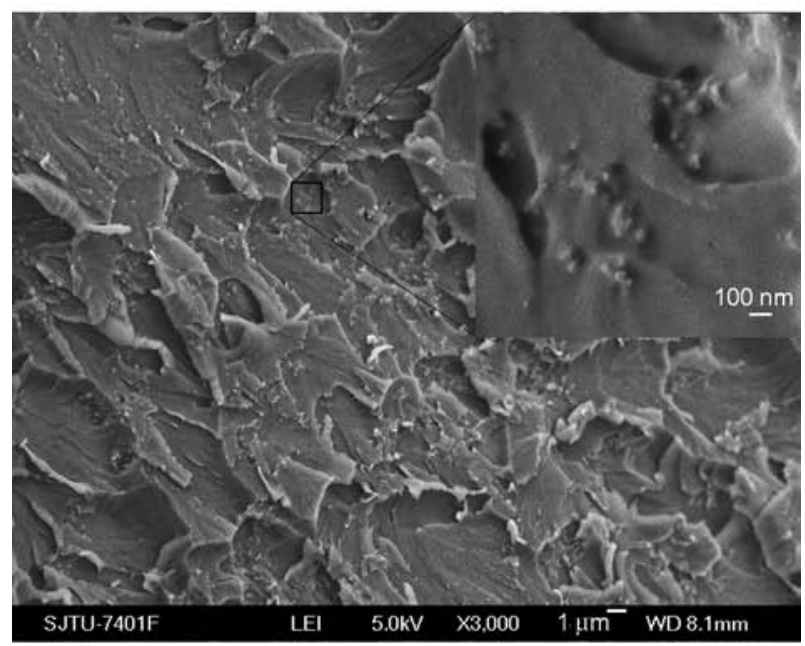

b)

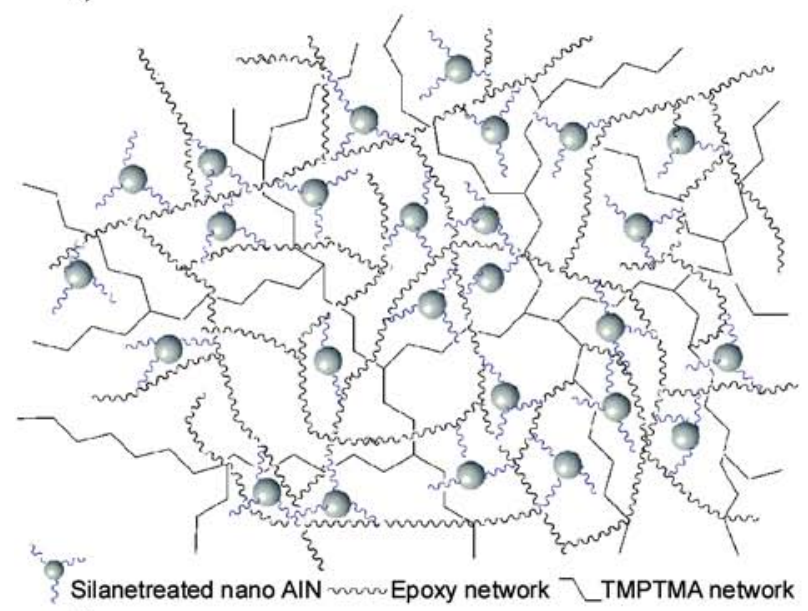

c)

Figure 4. FE-SEM micrograph of fracture surface of (a) A1, (b) A4, and (c) scheme for epoxy/TMPTMA system filled with silane treated nano-AlN. The inset in (b) is a magnificent showing the draw part.

\subsection{Thermal conductivity}

Figure 5a shows the variation of thermal conductivity of nano-AlN/epoxy/TMPTMA system as a func-
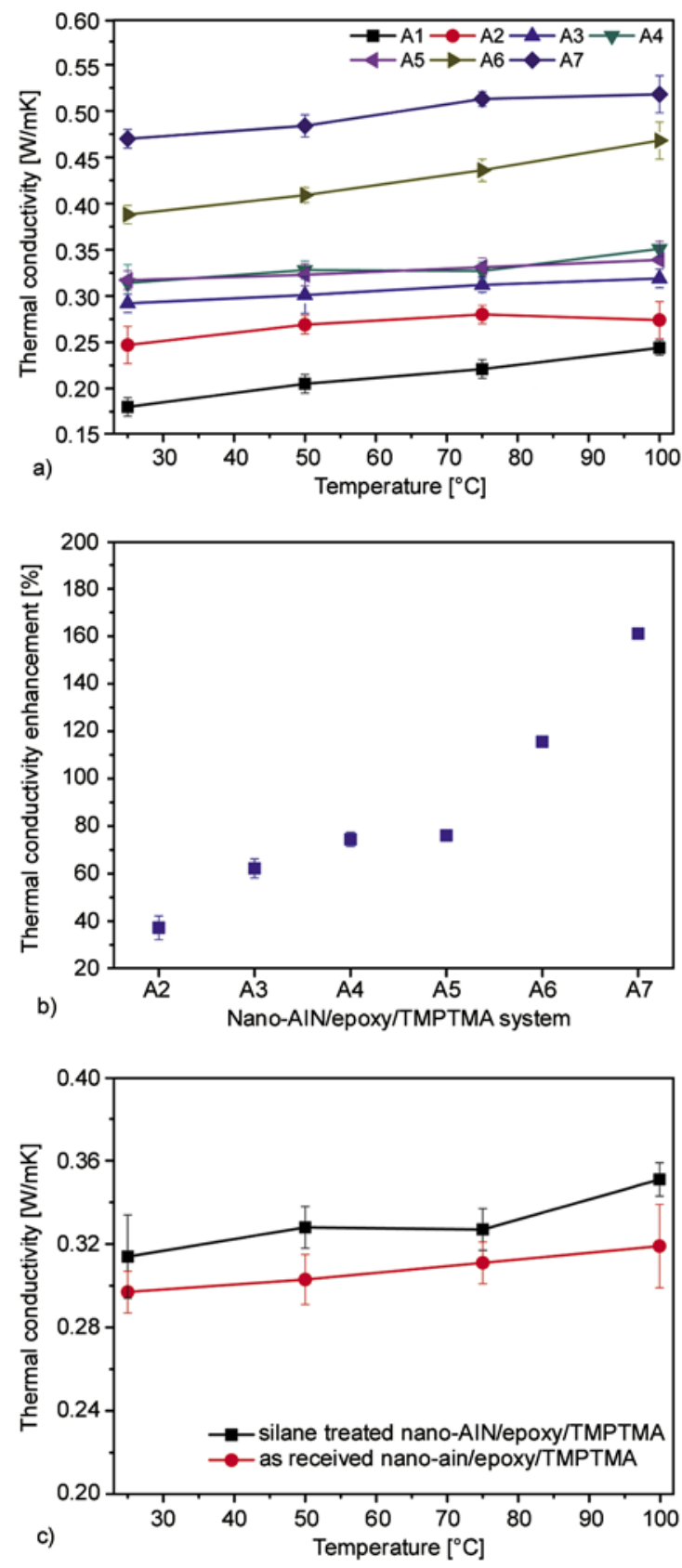

Figure 5. (a) thermal conductivity of nano-AlN/epoxy/ TMPTMA system. (b) thermal conductivity enhancement of nano-AlN/epoxy/TMPTMA system comparison with neat epoxy/TMPTMA system at $25^{\circ} \mathrm{C}$. (c) thermal conductivity of silane treated nano-AlN/epoxy/TMPTMA system and as received nano-AlN/epoxy/TMPTMA system with $5 \mathrm{wt} \%$ AlN loading.

tion of temperature. In the range from 25 to $100^{\circ} \mathrm{C}$, the absolute thermal conductivity of the nano-AlN/ epoxy/TMPTMA system increases, which is similar to the conclusion of Timofeeva et al. [8]. The experimental data also display that the thermal conductivity of nano-AIN/epoxy/TMPTMA system increased 
with increasing the nano-AlN filler loading. The thermal conductivity enhancement for nano-AlN/ epoxy/TMPTMA system containing different content nano-AlN filler is presented in Figure $5 \mathrm{~b}$. Here, $\lambda$ enhancement $(\%)=\left(\lambda_{1}-\lambda_{0}\right) / \lambda_{0}$, where $\lambda_{0}$ is the thermal conductivity of the neat epoxy/ TMPTMA system $(0.18 \mathrm{~W} /(\mathrm{m} \cdot \mathrm{K}))$ and $\lambda_{1}$ is the thermal conductivity of the nanocomposites due to the addition of nano-AlN filler at $25^{\circ} \mathrm{C}$. The results show that there is a $161 \%$ enhancement in thermal conductivity for A7. For the lower nano-AlN filler content (less than the percolation threshold), the main reason is attributed to that the covalent bridges minimize the interfacial phonon scattering and decrease the interface heat resistance by surface modification particles/epoxy resin. Various mechanisms have been presented to explain the increase of the effective thermal conductivity of composites containing different nanoparticles, such as interface interaction at the particle/resin interface [17], the nature of heat transport in the nanoparticles and the effects of nanoparticle clustering [18]. Based on our experimental results, it was concluded that the three dimensional network formed by the silane treated nano-AlN/epoxy dominates the thermal conduction mechanism, which leads to the nanocomposite with excellent thermal conductivity. Meanwhile, thermal conduction chains, the prevailing means to conduct thermal diffusion in the large-size filler/resin, are the secondary means to conduct thermal diffusion in the nanocomposites [13]. Figure $5 \mathrm{c}$ shows the detailed information for comparing the thermal conductivity of as received nano-AlN/epoxy/TMPTMA system and silane treated nano-AlN/epoxy/ TMPTMA system with $5 \mathrm{wt} \%$ AlN loading. We can see that the thermal conductivity of silane treated

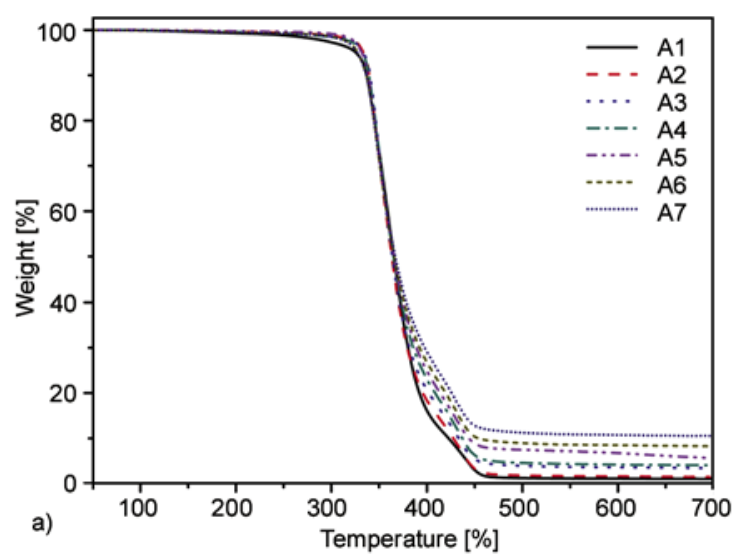

nano-AlN/epoxy/TMPTMA system is higher than that of as received nano-AlN/epoxy/TMPTMA system. It can be inferred that silane treatment is an effective approach to increase the thermal conductivity of nano-AlN/epoxy/TMPTMA system. The understanding of interface structure between nanoAIN fillers and the resin enables us to understand the thermal conduction mechanisms, therefore guides us to choose proper filler surface treatment approaches to gain excellent thermal conductivity. Furthermore, it also leads us to design the novel nanocomposites with high thermal conductivity.

\subsection{Thermal stability}

Thermal stability is very important for polymeric materials. In present study, the thermal stability of epoxy/TMPTMA system incorporated with the silane treated nano-AlN filler has been investigated by TGA by using heating rate of $10^{\circ} \mathrm{C} / \mathrm{min}$. Figure 6 shows the TG and DTG thermograms of the nanoAlN/epoxy/TMPTMA system. The weight loss of the system due to degradation is monitored as a function of temperature. The characteristic thermal parameters selected were the temperature for $5 \%$ and $10 \%$ weight loss and maximum degradation temperature, which is the highest thermal degradation rate temperature. The results are summarized in the Table 3. In case of neat epoxy/TMPTMA system, there is almost no weight loss up to $250^{\circ} \mathrm{C}$, but the degradation rate becomes very quick beyond that temperature, the main decomposition is degraded abruptly between $250^{\circ} \mathrm{C}$ and $410^{\circ} \mathrm{C}$. There exists a second decomposition reaction between 410 and $500^{\circ} \mathrm{C}$, which could be assigned to the decomposition reaction of TMPTMA network. The first decomposition reaction could be attributed to the decom-

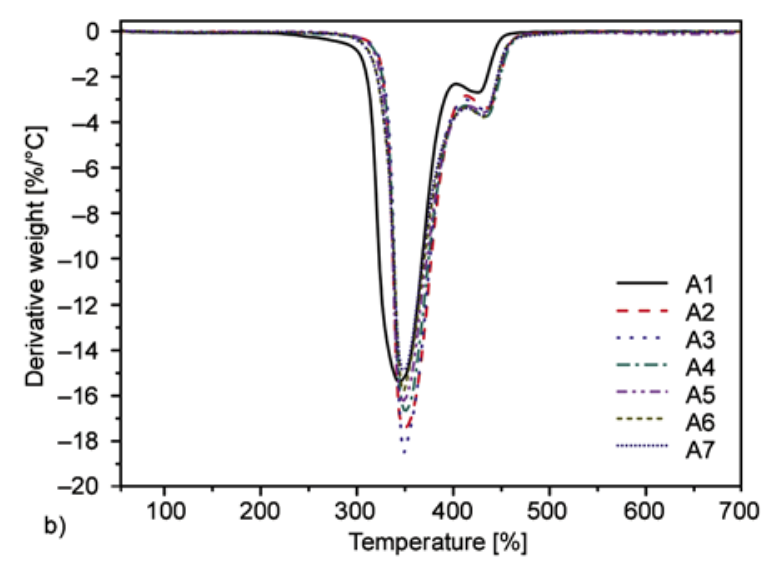

Figure 6. TGA (a) and DTG (b) curves of the nano-AIN/epoxy/TMPTMA system 
Table 3. Degradation properties of nano-AlN/epoxy/ TMPTMA system

\begin{tabular}{|c|c|c|c|c|}
\hline \multirow{2}{*}{ Sample } & \multicolumn{3}{|c|}{ Weight loss temperature [ ${ }^{\mathbf{}} \mathbf{C}$ ] } & Residue \\
\cline { 2 - 4 } & $\mathbf{T}_{\mathbf{5} \%}$ & $\mathbf{T}_{\mathbf{1 0}} \mathbf{\%}$ & $\mathbf{T}_{\mathbf{m a x}}$ & \\
\hline A1 & 326 & 336 & 340 & 0.9 \\
\hline A2 & 334 & 340 & 349 & 1.5 \\
\hline A3 & 334 & 340 & 349 & 3.4 \\
\hline A4 & 331 & 339 & 350 & 4.1 \\
\hline A5 & 331 & 339 & 348 & 5.7 \\
\hline A6 & 328 & 337 & 348 & 8.3 \\
\hline A7 & 329 & 337 & 349 & 10.5 \\
\hline
\end{tabular}

position reaction of epoxy network. This was in good agreement with the results from our previous study $[15,16]$. In the case of A2, incorporation of this small amount of the nano-AlN filler into the epoxy/TMPTMA system slightly improves the thermal stability because it increase the temperature at $5 \%$ weight loss by about $8^{\circ} \mathrm{C}$. The maximum degradation temperature $\left(T_{\max }\right)$ also increased by addition of the nano-AlN filler. However, higher loading of the nano-AlN filler does not lead to any further improvement of the thermal stability. The experimental results also show that the residual weight percent at $700^{\circ} \mathrm{C}$ of the nano-AlN/epoxy/ TMPTMA system increases upon addition of increasing amount of nano-AlN filler.

\subsection{Curing behavior}

In order to understand the influence of the silane treated nano-AlN filler on the epoxy/TMPTMA system in-depth, the curing behavior of all systems were investigated. The curing curves of A1 and A4 systems are shown in Figure 7. Shift of the DSC exothermic peaks to lower temperatures is observed in the presence of silane treated nano-AlN particles, illuminating that silane treated nano-AlN particles filled epoxy is obviously faster in reaching the

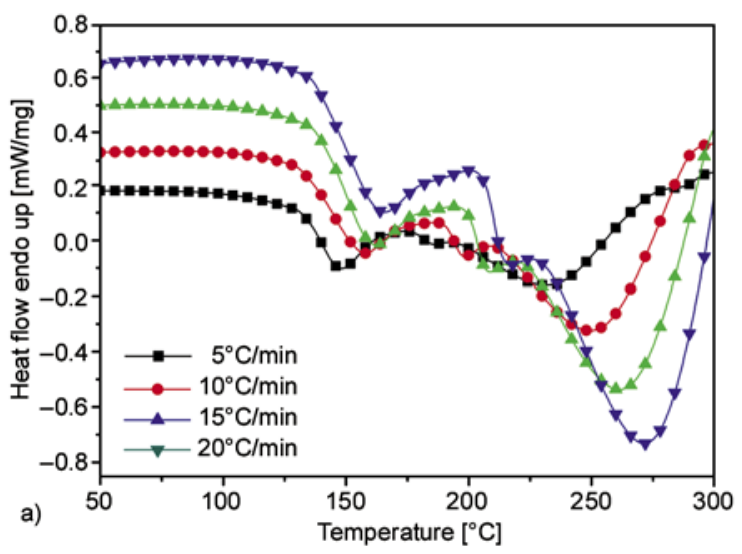

exothermic peak than neat epoxy/TMPTMA system. The curing mechanism of epoxy/TMPTMA system involves three stages consisting of radical reaction of TMPTMA, the adduct, and etherification reactions of epoxy/MeHHPA. The third stage (i.e., the etherification reaction) dominates the cure process and is discussed mainly in this study.

The exothermic peak temperatures $\left(T_{\mathrm{p}}\right)$ and the heats of the reaction $(\Delta H)$ for A1-A7 systems are summarized in Table 4. From Table 4, it is clear that silane treated nano-AlN particles act as catalyst and facilitate the curing at the initial curing stage by lowering $T_{\mathrm{p}}$. For the development of the composites, the cure acceleration effect caused by silane treated nano-AlN particles could bring positive effect on the processing of composite since it needs shorter pre-cure time or lower pre-temperature. In this study, this accelerating effect might also be partially attributed to the remaining hydroxyl groups $(-\mathrm{OH})$ and amino groups $\left(-\mathrm{NH}_{2}\right)$ on the surface of nano-AlN particles since the epoxy/TMPTMA system was used as the martrix. The total heats of reaction $(\Delta H)$ of all the studies systems which are calculated by the total area under the exothermic peaks are reported in Table 4. The result indicate that the inclusion of silane treated nano-AlN parti-

Table 4. Curing kinetic parameters of the nano-AlN/epoxy/ TMPTMA system and glass transition temperatures $\left(T_{\mathrm{g}}\right)$ of the cured systems

\begin{tabular}{|c|c|c|c|c|}
\hline System & $\mathbf{T}_{\mathbf{p}}\left[{ }^{\mathbf{0}} \mathbf{C}\right]$ & $\mathbf{\Delta} \mathbf{H} \mathbf{J} / \mathbf{g})$ & $\mathbf{E}_{\mathbf{a}}[\mathbf{k J} / \mathbf{m o l}]$ & $\mathbf{T}_{\mathbf{g}}\left[{ }^{\mathbf{0}} \mathbf{C}\right]$ \\
\hline A1 & 249.8 & 130.4 & 83.28 & 176.4 \\
\hline A2 & 227.6 & 137.3 & 71.27 & 180.0 \\
\hline A3 & 222.7 & 139.9 & 53.13 & 180.1 \\
\hline A4 & 222.7 & 139.6 & 68.85 & 181.4 \\
\hline A5 & 216.2 & 154.0 & 64.54 & 177.9 \\
\hline A6 & 222.3 & 132.1 & 77.20 & 181.8 \\
\hline A7 & 222.0 & 137.8 & 73.81 & 186.7 \\
\hline
\end{tabular}

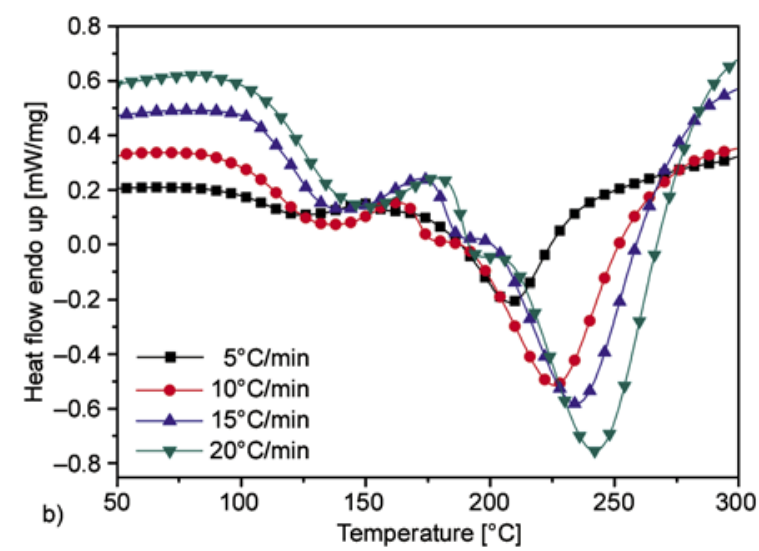

Figure 7. Dynamic DSC curves with different heating rates of (a) A1 and (b) A4 
cles increases the $\Delta H$, possibly due to the addition of epoxy concentration in the composite.

From a dynamic DSC run, the total area $S$ of the exothermal peak (the region between the exotherm and the baseline) is in direct proportion to the $\Delta H$ release during the whole cure reaction. The fraction extent of conversion $\alpha$ at any temperature $T$ can be expressed by Equation (1):

$\alpha=\frac{\Delta H_{\mathrm{T}}}{\Delta H}=\frac{S_{\mathrm{T}}}{S}, \quad 0 \leq \alpha \leq 1$

where $\Delta H_{\mathrm{T}}$ is the heat of reaction of partially cured samples heated up to the temperature $T$. A comparison of the curing process, at $10^{\circ} \mathrm{C} / \mathrm{min}$ heating rates, among the neat epoxy/TMPTMA system and the silane treated nano-AlN particles filled epoxy/ TMPTMA systems is shown in Figure 8. It confirms that the silane treated nano-AlN particles act as catalyst at the initial curing stage again. Furthermore, a sigmoidal form of the curves, which is indicative of an autocatalytic kinetics of all the studies systems, is observed. That is to say, the addition of the silane treated nano-AlN particles does not change the autocatalytic cure reaction mechanism of the epoxy/TMPTMA system. It can be seen that all $\alpha$ values increased very slowly at the beginning. When the temperature is high enough, the $\alpha$ values are raise rapidly over $90 \%$, and then they are leveled off.

Ozawa Equation (2), which was concluded to be independent of the order of reaction, is used to calculate the cure reaction activation energy $E_{\mathrm{a}}$ $[19,20]$.

$\frac{\mathrm{d}(-\ln \beta)}{\mathrm{d}\left(\frac{1}{T_{\mathrm{p}}}\right)}=1.052 \frac{E_{\mathrm{a}}}{R}$

The value of $E_{\mathrm{a}}$ can be determined from the slope of the plot of $-\ln \beta$ versus $1 / T_{\mathrm{p}}$. Furthermore, the influence of the silane treated nano-AlN particles on the $E_{\text {a }}$ parameters of A1-A7 systems was also studied. The calculated values of $E_{\mathrm{a}}$ of A1-A7 systems are reported in Table 4 . The decreased of values of $E_{\mathrm{a}}$ for the filled system also implied that the nano-AlN particles facilitate the curing process. Since the effect of increased concentration of the silane coupling agent was equal to the effect of increase the crosslinking density in the curing system, it is understandable of the decrease values of $E_{\mathrm{a}}$ when the

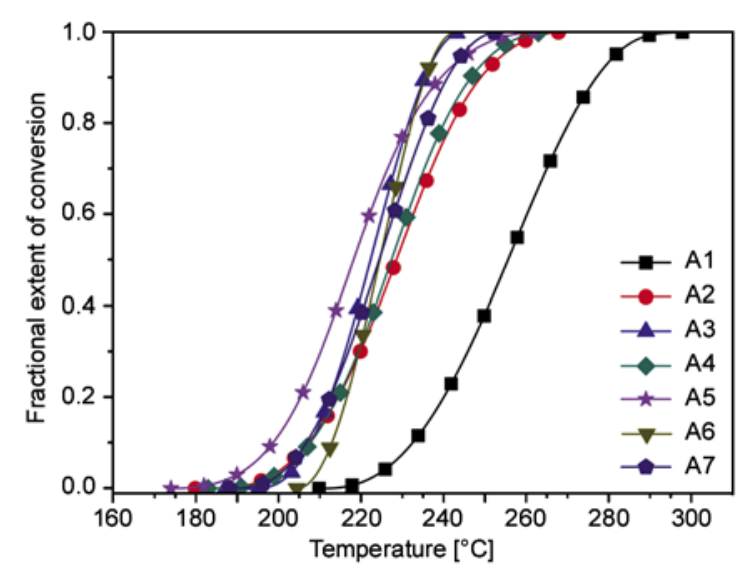

Figure 8. Conversion versus temperature plot at $10^{\circ} \mathrm{C} / \mathrm{min}$ heating rates of the $\mathrm{A} 1-\mathrm{A} 7$ systems

nano-AlN particles coupled with higher concentration of the silane coupling agent. But the $E_{\mathrm{a}}$ does not show any trend on increasing the amount of the nano-AlN particles.

During the cure reaction, the system undergoes gelation (liquid-to-rubber) and vitrification (rubberto-glass) transitions. As the cure reaction proceeds, it is the possible that the glass transition temperature $\left(T_{\mathrm{g}}\right)$ increases over the curing temperature $\left(T_{\mathrm{c}}\right)$, this phenomenon is called vitrification. [21] From Table 4, the $T_{\mathrm{gS}}$ of the silane treated nano-AlN particles filled epoxy/TMPTMA systems are found to higher than that of the neat epoxy/TMPTMA system. Meanwhile, the $T_{\mathrm{gS}}$ of the silane treated nanoAlN particles filled epoxy/TMPTMA systems were improved with increasing content of the silane treated nano-AlN particles, although A5 system deviates from this trend. The glass transition in polymers in a complex phenomenon that in influenced by many factors including free volume, molecular mobility, molecular weigh, and crosslink density $[22,23]$. When the silane treated nano-AlN particles are introduced into systems, there would result in increased $T_{\mathrm{g}}$. There could be the main reason that the epoxide groups is the end group of silane coupling agent which wound result in a higher crosslinking density in epoxy/TMPTMA system.

\section{Conclusions}

The influences of nano-AlN particles on the thermal conductivity, thermal stability and the curing reaction of CER/TMPTMA systems have been investigated. The thermal conductivity of A7 system was up to $0.47 \mathrm{~W} /(\mathrm{m} \cdot \mathrm{K})$, which is $161 \%$ 
increase when compared with the neat epoxy/ TMPTMA system. Incorporation of a small amount of the nano-AlN filler into the epoxy/TMPTMA system improves the thermal stability. However, higher loading of the nano-AlN filler does not lead to any further improvement of the thermal stability. For instance, the thermal degradation temperature at $5 \%$ weight loss for $\mathrm{A} 2$ system was improved by $\sim 8^{\circ} \mathrm{C}$ over the neat epoxy/TMPTMA system.

The resulting fractional extent of conversion versus temperature curves of all the systems considered present the same sigmoidal functional form which is indicative of an autocatalytic kinetics, that is to say, the addition of silane treated nano-AlN particles does not change the cure reaction mechanism. For the development of the nanocomposite, the cure acceleration effect caused by silane treated nanoAlN particles could bring positive effect on the processing of composite since it needs shorter pre-cure time and lower pre-temperature, meanwhile the increase of glass transition temperature of nanocomposite would bring the positive effect to improve the heat resistance.

\section{References}

[1] Yu A. P., Ramesh P., Sun X. B., Bekyarova E., Itkis M. E., Haddon R. C.: Enhanced thermal conductivity in a hybrid graphite nanoplatelet - Carbon nanotube filler for epoxy composites. Advanced Materials, 20, 47404744 (2008). DOI: 10.1002/adma.200800401

[2] Veca L. M., Meziani M. J., Wang W., Wang X., Lu F., Zhang P., Lin Y., Fee R., Connell J. W., Sun Y-P.: Carbon nanosheets for polymeric nanocomposites with high thermal conductivity. Advanced Materials, 21, 2088-2092 (2009).

DOI: $10.1002 / \mathrm{adma} .200802317$

[3] Cheng J., Li J., Zhang J. Y.: Curing behavior and thermal properties of trifunctional epoxy resin cured by 4,4'-diaminodiphenyl sulfone. Express Polymer Letters, 3, 501-509 (2009). DOI: $10.3144 /$ expresspolymlett.2009.62

[4] Zhang J., Xu Y. C., Huang P.: Effect of cure cycle on curing process and hardness for epoxy resin. Express Polymer Letters, 3, 534-541 (2009).

DOI: 10.3144 /expresspolymlett.2009.67

[5] Philipp M., Gervais P. C., Sanctuary R., Müller U., Baller J., Wetzel B., Wetzel B., Krüger J. K.: Effect of mixing sequence on the curing of amine-hardened epoxy/alumina nanocomposites as assessed by optical refractometry. Express Polymer Letters, 2, 546-552 (2008).

DOI: $10.3144 /$ expresspolymlett.2008.66
[6] Procter P., Solc J.: Improved thermal conductivity in microelectronic encapsulants. IEEE Transactions on Components Hybrids and Manufacturing Technology, 14, 708-713 (1991). DOI: $10.1109 / 33.105121$

[7] Huang X. Y., Jiang P. K., Xie L. Y.: Ferroelectric polymer/silver nanocomposites with high dielectric constant and high thermal conductivity. Applied Physics Letters, 95, 242901/1-242901/3 (2009).

DOI: $10.1063 / 1.3273368$

[8] Timofeeva E. V., Gavrilov A. N., McCloskey J. M., Tolmachev Y. V., Sprunt S., Lopatina L. M., Selinger J. V.: Thermal conductivity and particle agglomeration in alumina nanofluids: Experiment and theory. Physical Review E, 76, 061203/1-061203/16 (2007).

DOI: 10.1103/PhysRevE.76.061203

[9] Xu Y., Chung D. D. L., Mroz C.: Thermally conducting aluminum nitride polymer-matrix composites. Composites Part A: Applied Science and Manufacturing, 32, 1749-1757 (2001).

DOI: $10.1016 / \mathrm{S} 1359-835 \mathrm{X}(01) 00023-9$

[10] Wang W., Yang X., Fang Y., Ding J., Yan J.: Enhanced thermal conductivity and thermal performance of form-stable composite phase change materials by using $\beta$-aluminum nitride. Applied Energy, 86, 11961200 (2009).

DOI: 10.1016/j.apenergy.2008.10.020

[11] Pezzotti G., Kamada I., Miki S.: Thermal conductivity of AlN/polystyrene interpenetrating networks. Journal of the European Ceramic Society, 20, 1197-1203 (2000).

DOI: $10.1016 / \mathrm{S} 0955-2219(99) 00282-4$

[12] Li T-L., Hsu S. L-C.: Enhanced thermal conductivity of polyimide films via a hybrid of micro- and nanosized boron nitride. Journal of Physical Chemistry B, 114, 6825-6829 (2010).

DOI: $10.1021 / j p 101857 \mathrm{~W}$

[13] Zhou T. L., Wang X., Gu M. Y., Liu X. H.: Study of the thermal conduction mechanism of nano-SiC/DGEBA/ EMI-2,4 composites. Polymer, 49, 4666-4672 (2008). DOI: $10.1016 /$ j.polymer.2008.08.023

[14] Michael M., Nguyen L.: Effect of mold compound thermal-conductivity on IC package thermal performance. in 'InterSociety Conference on Thermal Phenomena in Electronic Systems, 1992. I-THERM III, Austin, USA' 246-252 (1992). DOI: 10.1109/ITHERM.1992.187769

[15] Duan J., Kim C., Jiang P. K.: On-line monitoring of cycloaliphatic epoxy/acrylate interpenetrating polymer networks formation and characterization of their mechanical properties. Journal of Polymer Research, 16, 45-54 (2009). DOI: $10.1007 / \mathrm{s} 10965-008-9201-7$ 
[16] Duan J., Kim C., Zheng Y., Jiang P. K.: Morphology and thermal and dielectric behavior of cycloaliphatic epoxy/trimethacrylate interpenetrating polymer networks for vacuum-pressure-impregnation electrical insulation. Journal of Applied Polymer Science, 110, 566-576 (2008).

DOI: $10.1002 / a p p .28835$

[17] Yu W., Choi S. U. S.: The role of interfacial layers in the enhanced thermal conductivity of nanofluids: A renovated Maxwell model. Journal of Nanoparticle Research, 5, 167-171 (2003).

DOI: $10.1023 / \mathrm{A}: 1024438603801$

[18] Chen H., Ding Y., He Y., Tan C.: Rheological behaviour of ethylene glycol based titania nanofluids. Chemical Physics Letters, 444, 333-337 (2007). DOI: $10.1016 /$ j.cplett.2007.07.046

[19] Ozawa T.: Estimation of activation energy by isoconversion methods. Thermochimica Acta, 203, 159-165 (1992).

DOI: $10.1016 / 0040-6031(92) 85192-X$
[20] Ozawa T.: A new method of analyzing thermogravimetric data. Bulletin of the Chemical Society of Japan, 38, 1881-1886 (1965).

DOI: $10.1246 /$ bcsj.38.1881

[21] Zhou T., Wang X., Liu X., Xiong D.: Influence of multi-walled carbon nanotubes on the cure behavior of epoxy-imidazole system. Carbon, 47, 1112-1118 (2009).

DOI: $10.1016 /$ j.carbon.2008.12.039

[22] White S. R., Mather P. T., Smith M. J.: Characterization of the cure-state of DGEBA-DDS epoxy using ultrasonic, dynamic mechanical, and thermal probes. Polymer Engineering and Science, 42, 51-67 (2002). DOI: 10.1002/pen.10927

[23] Allaoui A., El Bounia N.: How carbon nanotubes affect the cure kinetics and glass transition temperature of their epoxy composites? - A review. Express Polymer Letters, 3, 588-594 (2009).

DOI: $10.3144 /$ expresspolymlett.2009.73 